Original Research Paper

\title{
Synthesis and Characterization of Marine Clay-Supported Nano Zero Valent Iron
}

\author{
Ho Kuok How and Wan Zuhairi Wan Yaacob \\ Program Geology, School of Environmental Science and Natural Resources, \\ Faculty Science and Technology, National University of Malaysia, Bangi, 43600 Selangor, Malaysia
}

Article history

Received: 13-01-2014

Revised: 03-06-2015

Accepted: 22-06-2015

Corresponding author:

Ho Kuok How

Program Geology, School of

Environmental Science and

Natural Resources, Faculty

Science and Technology, National

University of Malaysia, Bangi,

43600 Selangor, Malaysia

Email: hokuokhow@gmail.com

\begin{abstract}
This study reports the preparation and characterization of marine clay nano zero valent iron $(\mathrm{MC}+\mathrm{nZVI})$ where marine clay acts as the composite material. Marine clay was air dried and pulverized before used. Basically, MC+nZVI was synthesized by chemical reduction method. The materials synthesized were left oven dried overnight at $50^{\circ} \mathrm{C}$. The obtained materials were characterized by Field Emission Scanning Electron Microscopy (FESEM), Transmission Electron Microscopy (TEM), X-ray Photoelectron Spectroscopy (XPS), X-Ray Diffraction (XRD) and Fourier Transform Infrared (FTIR). FESEM images show that the nZVI particles dispersed well on the surface of marine clay thus reducing aggregation of nZVI. TEM images show that the particles have the shell-core structure and the particles sizes were around 29.92-57.11 nm for MC+nZVI. XPS spectrums indicate the existence of $\mathrm{Fe}^{0}$ on the synthesized MC+nZVI. Other than that, XRD and FTIR results also show that there exists the formation of iron oxides on the surface of MC+nZVI. The adsorption capability of $\mathrm{MC}+\mathrm{nZVI}$ is increased by $15 \%$ compared to marine clay. Therefore, increment of $\mathrm{MC}+\mathrm{nZVI}$ adsorption capacity might be due to the welldispersed nZVI thus enhancing the performance of MC+nZVI.
\end{abstract}

Keywords: Marine Clay, Nano Zero Valent Iron, Adsorption

\section{Introduction}

Lead $(\mathrm{Pb})$ is one of the heavy metals found in the ex mining area, industrial and manufacturing waste especially in paint industry (Abadin et al., 2007; Ashraf et al., 2010). $\mathrm{Pb}$ contaminates the environment thus affecting the living species. This could lead to severe health problem such as amnesia, organ failure and even death. So, removing $\mathrm{Pb}$ to minimize the contamination is important to ensure the safety of the living species.

Recent technology has introduced the use of nano zero valent iron (nZVI) which is so reactive that it can effectively remove high amount of $\mathrm{Pb}$ (II) (Zhang et al., 2010). In addition, nZVI has proven to be able to remediate water contaminated with chlorinated organic compounds (Dorathi and Kandasamy, 2012; Su et al., 2012), dyes (Poursaberi et al., 2012), phenol (Mystrioti et al., 2012), arsenic (Kanel et al., 2005), heavy metals (Boparai et al., 2011; Liu et al., 2014; Yuan et al., 2009). Due to the small particle size of nZVI, it provides a great amount of surface area to react with the heavy metals. However,
nZVI tends to agglomerate forming a larger size particle reducing the surface area and its reactivity. nZVI is also easily oxidized to $\mathrm{Fe}$ (II) or Fe (III) when exposed to the air and water (O'Carroll et al., 2013). Other than that, conflicts occurred on delivering nZVI particles to the contaminated zone due to the density of iron, long range magnetic forces (Lin et al., 2010; Tiraferri and Sethi, 2008) and ionic strength in groundwater which increase the potential of aggregation (Phenrat et al., 2007).

The challenges of nano zero valent iron aggregation and fast oxidation state are overcome with various methods. Polymer such as Poly Arcrylic Acid (PAA) and Carboxymethyl Cellulose (CMC) were used to enhance the migration or transportation of nZVI particles (Lin et al., 2010). This experiment has demonstrated that the particles size of the stabilized nZVI particles is in nano size. Bidentate bridging of the bonding via the carboxylic group, which provides electrostatic and steric repulsion, prevents aggregation of the particles. Furthermore, other methods such as the use of clay materials (for example montmorillonite, kaolinite 
and zeolite) as composite materials to reduce aggregation of nZVI have also been proven to be useful for heavy metals adsorption. The composite materials have successfully eliminated aggregation and nZVI particles are well dispersed within the zeolite matrix (Kim et al., 2013). nZVI particles also showed less aggregation and better dispersion with the enhancement of montmorillonite (Bhowmick et al., 2014; Yuan et al., 2009).

The objectives of this study are to synthesis nZVI with marine clay as composite material, to characterize the composite material of marine clay and nZVI $(\mathrm{MC}+\mathrm{nZVI})$ and to test the removal capacity of $\mathrm{Pb}$ by $\mathrm{MC}+\mathrm{nZVI}$. The study reports the characteristics of the composite materials. Field emission scanning electron microscopy (FESEM) and Transmission Electron Microscopy (TEM) are used to examine the morphology of MC + nZVI. Characteristics of MC + nZVI are further investigated using X-Ray Diffraction (XRD), Fourier Transform Infrared Spectroscopy (FTIR) and X-ray Photoelectron Spectroscopy (XPS). To investigate the removal capacity of $\mathrm{MC}+\mathrm{nZVI}$, batch test are conducted.

\section{Methods and Materials}

All chemicals are purchased from Fisher Scientific with high purity and were used as received, including iron (III) chloride hexahydrate, $\mathrm{FeCl}_{3} \cdot 6 \mathrm{H}_{2} \mathrm{O}$ (Acros organics, 99+\%), sodium borohydride, $\mathrm{NaBH}_{4}$ (Acros organics, 98+\%) and absolute ethanol (Fisher Scientific, 99.4\%). Composite material used is marine clay collected from Selangor, Malaysia. All stock solutions were prepared by lead (II) nitrate, $\mathrm{Pb}\left(\mathrm{NO}_{3}\right)_{2}$ (Merck, analysis grade) with deionized water.

Synthesizing marine clay nano zero valent iron (MC+nZVI). Bare nZVI was prepared using chemical reduction method (Sun et al., 2006; Zhang et al., 2010). $4.83 \mathrm{~g}$ of $\mathrm{FeCl}_{3} \cdot 6 \mathrm{H}_{2} \mathrm{O}$ was dissolved in ethanol solution of $35 \mathrm{~mL}$ deionized water and $15 \mathrm{~mL}$ ethanol to produce ferric solution. $4 \mathrm{~g}$ of marine clay was added into the ferric solution. The mixture of ferric solution and composite materials were left in an ultrasonic shaker for $30 \mathrm{~min}$ (Uzum et al., 2009) before adding in $\mathrm{NaBH}_{4}$ solution. Then, $6.091 \mathrm{~g}$ of $\mathrm{NaBH}_{4}$ was dissolved in $100 \mathrm{~mL}$ of deionized water. $\mathrm{NaBH}_{4}$ was added into ferric solution on a magnetic stirrer with $1000 \mathrm{rpm}$. The drop rate of $\mathrm{NaBH}_{4}$ was controlled at 60-70 drop per minutes. On the first drop of $\mathrm{NaBH}_{4}$, black particles can be observed in the ferric solution. The mixture was left to stir for another $30 \mathrm{~min}$ after the last drop of $\mathrm{NaBH}_{4}$. Vacuum filtration was used to separate the liquid phase solution and the solid black particles. The solid black particles were washed thrice with $50 \mathrm{~mL}$ of absolute ethanol and oven dried overnight at $50^{\circ} \mathrm{C}$ (Uzum et al., 2009).

\section{Characterization: \\ Transmission \\ Electron Microscopy (TEM)}

TEM characterization was performed using Philips CM 12 electron microscopy operating at an acceleration voltage of $120 \mathrm{kV}$. Samples were added into ethanol and dispersed using ultrasonic shaker for $5 \mathrm{~min}$. A drop of dispersion was applied onto a copper grid and dried in a fume hood. Then, the samples were transferred into the microscope to be analyzed.

\section{Fourier Transform Infrared (FTIR)}

FTIR spectra of marine clay and MC + nZVI were obtained using Nicolet 6700 . Samples were prepared by mixing $\mathrm{KBr}$ powder and pressing the mixture into a sheer slice. The wavelength obtained was in between 400 to $4000 \mathrm{~cm}^{-1}$.

\section{$X$-ray Photoelectron Spectroscope (XPS)}

XPS is used to measure the surface chemical composition and elements' valence of $\mathrm{MC}+\mathrm{nZVI}$. The analysis was conducted with X-ray photoelectron spectrometer of the Kratos, Axis Ultra DLD. The hemispherical analyzer provides both high-energy resolution and high sensitivity spectroscopic performance. Exceptional small spot capabilities $(<15$ $\mu \mathrm{m})$ are achieved via a series of selected area apertures used in combination with the magnetic and electrostatic lenses. In parallel imaging mode photoelectrons are transferred to the patented spherical mirror analyzer to produce real time chemical state images with less than 3 $\mu \mathrm{m}$ spatial resolution. Binding energies calibration of the spectra was achieved with aliphatic adventitious hydrocarbon $\mathrm{C}(1 \mathrm{~s})$ peak at $284.6 \mathrm{eV}$.

\section{$X$-ray Diffraction $(X R D)$}

XRD patterns of marine clay and $\mathrm{MC}+\mathrm{nZVI}$ were obtained by Bruker/D8 Advance with a high power $\mathrm{Cu}-\mathrm{K}_{\alpha}$ radioactive source at $40 \mathrm{kV} / 40 \mathrm{~mA}$. Continuous scans from $5^{\circ}$ to $80^{\circ} 2 \theta$ were collected at the rate of $3^{\circ}$ of $2 \theta$ per minute.

\section{Batch test}

Throughout the experiment, $\mathrm{Pb}$ solution was used as the main heavy metal contaminant. $\mathrm{Pb}$ solution was prepared by dissolving $0.7993 \mathrm{~g}$ of $\mathrm{Pb}\left(\mathrm{NO}_{3}\right)_{2}$ in 1000 $\mathrm{mL}$ of distilled water to yield $500 \mathrm{mg} \mathrm{L}^{-1}$ stock solutions. These solutions were then diluted to lower concentration for experimental purposes. The experiments were carried out in room temperature in a $40 \mathrm{~mL}$ centrifuge tubes. The tubes were kept on the orbital shaker at $250 \mathrm{rpm}$ and then centrifuge at 3000 $\mathrm{rpm}$. The supernatant solutions were transferred to another centrifuge tube and then diluted for analysis. 
The concentration of the supernatant solutions was determined by AAS. This analysis is carried out with Atom PerkinElmer AA 800 that is operated by computer with the software of AA WinLab32.

To determine the optimum dosage, different dosage of materials $(0.01,0.03,0.05,0.07,0.1,0.3,0.5,0.7,1.0$ $\mathrm{g})$ were used. The certain dosage was added into a $50 \mathrm{mg}$ $\mathrm{L}^{-1}$ of $\mathrm{Pb}$ solution in a $40 \mathrm{~mL}$ centrifuge tube. The tubes were shaken for an hour with $250 \mathrm{rpm}$ and later centrifuged with $3000 \mathrm{rpm}$ for $5 \mathrm{~min}$.

In order to reveal the general adsorption capacity of marine clay and $\mathrm{MC}+\mathrm{nZVI}$, screening effect test was done. The analysis was carried out in a ratio of mass to volume solution that is $1: 10$. The samples were added into $100 \mathrm{mg} \mathrm{L}^{-1} \mathrm{~Pb}$ solutions in a $40 \mathrm{~mL}$ centrifuge tube and shaken with $250 \mathrm{rpm}$ for $2 \mathrm{~h}$. The solutions were then centrifuged at $3000 \mathrm{rpm}$ for $5 \mathrm{~min}$.

\section{Result and Discussion}

\section{Characterization-TEM and FESEM}

The morphologies of the MC+nZVI and marine clay were identified from TEM and FESEM images as shown in Fig. 1. MC+nZVI particles showed homogenous rounded particles with size ranged from 29 to $57 \mathrm{~nm}$. Chain-liked particle of nZVI was hardly observed in TEM image shown in Fig. 1a thus proving marine clay can act as supported material reducing aggregation thus presenting a finer particle size. Stable dispersion of nZVI in marine clay might increase the mechanical strength of nZVI (Zhang et al., 2011). As shown in the TEM image of MC+nZVI, thin layer of oxide shell can be observed. The dark portions observed inside the oxide shell is $\mathrm{Fe}^{0}$ (Giasuddin et al., 2007). Figure $1 \mathrm{~b}$ showed the TEM image of marine clay. The texture of marine clay was flaky and blocky. It is clear with patches of dark spot, which may be due to the existing of opaque mineral in the marine clay. We can observe opaque mineral like iron, carbon and magnesium existing in marine clay from the EDX of FESEM as shown in Fig. 1c.

Figure 1d showed the FESEM image of MC+nZVI with nZVI particles dispersed well on the surface of marine clay forming individual nano particle. Chain-like particles were hardly observed from the MC+nZVI image as well. This showed that MC is able to act as a composite material to reduce aggregation from nZVI. With the decrease of aggregation, the mechanical strength might be increased.

\section{FTIR Analysis}

FTIR Spectra was obtained between the ranges of 4000-400 $\mathrm{cm}^{-1}$. Figure 2 shows the spectra of marine clay and MC+nZVI. Comparing the FTIR spectra of marine clay and $\mathrm{MC}+\mathrm{nZVI}$, the adsorption peaks around $3693.8 \mathrm{~cm}^{-1}$ to $3620 \mathrm{~cm}^{-1}$ which correspond to the O$\mathrm{H}$ vibration of $\mathrm{H}_{2} \mathrm{O}$ molecule had reduced significantly. Strong adsorption peaks observed in FTIR spectra of marine clay at the range of 900-1100 $\mathrm{cm}^{-1}$ indicates the functional group of silicate ion (Coates, 2000). The adsorption peaks had reduced in FTIR spectra of MC+nZVI due to the destruction of $\mathrm{Si}-\mathrm{O}$ bonds by alkali, resulting from the reaction of $\mathrm{NaBH}_{4}$ and $\mathrm{H}_{2} \mathrm{O}$ during preparation of nZVI (Frost and Johanssont, 1998; Yuan et al., 2008; Zhang et al., 2011). New adsorption peaks at the range of 532.7$466.4 \mathrm{~cm}^{-1}$ indicating $\mathrm{Fe}-\mathrm{O}$ stretching of $\mathrm{Fe}_{2} \mathrm{O}_{3}$ and $\mathrm{Fe}_{3} \mathrm{O}_{4}$ were observed. The result obtained is similar to reported data by Zhang et al. (2011).

\section{X-Ray Photoelectron Spectroscope Analysis (XPS)}

Figure 3 shows the XPS spectrum of MC+nZVI. XPS shows that the elements existed on surface of MC+nZVI were $\mathrm{Fe}, \mathrm{O}$ with abundance followed by $\mathrm{C}, \mathrm{Si}$ and $\mathrm{Al}$. The presence of $\mathrm{Na}$ was expected as $\mathrm{NaBH}_{4}$ was used to synthesize $\mathrm{MC}+\mathrm{nZVI}$. Thus, the elements mentioned can be observed on the surface of MC+nZVI. Binding energies of the elements were Al 2p 75.0 eV, Si 2p 104.0 $\mathrm{eV}, \mathrm{C} 1 \mathrm{~s} 285.0 \mathrm{eV}$ and O 1s $532.0 \mathrm{eV}$ (Kim et al., 1994). $\mathrm{Fe} 2 \mathrm{p}$ orbit is shown in Fig. $3 \mathrm{~b}$. Binding energies for $\mathrm{Fe}$ $2 \mathrm{p}_{3 / 2}$ were $708.4 \mathrm{eV}$ and $710.3 \mathrm{eV}$ while Fe $2 \mathrm{p}_{1 / 2}$ were $722.0 \mathrm{eV}$ and $723.9 \mathrm{eV}$. These four peaks indicate that the nZVI loaded on the surface of marine clay was in the form of $\mathrm{FeO}$ and $\mathrm{Fe}_{3} \mathrm{O}_{4}$. Small peaks at $706.1 \mathrm{eV}$ and $719.7 \mathrm{eV}$ corresponding to zero valent iron $\left(\mathrm{Fe}^{0} 2 \mathrm{p}_{3 / 2}\right.$ and $\mathrm{Fe}^{0} 2 \mathrm{p}_{1 / 2}$ respectively) can be observed (Sun et al., 2006; Zhang et al., 2011). The subtle peak of $\mathrm{Fe}^{0}$ is due to the high surface sensitivity of XPS (Zhang et al., 2011).

\section{X-Ray Diffraction Analysis (XRD)}

XRD patterns are shown in Fig. 4. XRD patterns indicated that marine clay contained kaolinite and montmorillonite as clay mineral and quartz, non clay mineral. The sharp peak at $2 \theta=12.05^{\circ}$ and $50.116^{\circ}$ represent kaolinite whereas at $2 \theta=5.8719^{\circ}$ represents montmorillonite. The peak at $2 \theta=20.8442^{\circ}$ and $26.6238^{\circ}$ represent quartz. Kaolinite, montmorillonite and quartz peaks were still observable in the $\mathrm{MC}+\mathrm{nZVI}$ XRD spectra. The sharp diffraction peak at $2 \theta=44.9^{\circ}$ corresponded to the formation of zero valent iron, $\mathrm{Fe}^{0}$ lattice planes (110) (Lin et al., 2010). This indicated that $\mathrm{Fe}^{0}$ nano particles were supported on the marine clay surface (Zhang et al., 2011). Furthermore, lepidocrocite $\left(\mathrm{Fe}_{2} \mathrm{O}_{3} \cdot \mathrm{H}_{2} \mathrm{O}\right)$ and tincalconite $\left(\mathrm{Na}_{2}\left[\mathrm{~B}_{4} \mathrm{O}_{5}(\mathrm{OH})_{4}\right] \cdot 3 \mathrm{H}_{2} \mathrm{O}\right)$ were two other elements observed in MC-nZVI XRD spectra. Lepidocrocite was produced in nZVI whereas tincalconite was produced due to the reduction process by $\mathrm{NaBH}_{4}$ while synthesizing nZVI. 


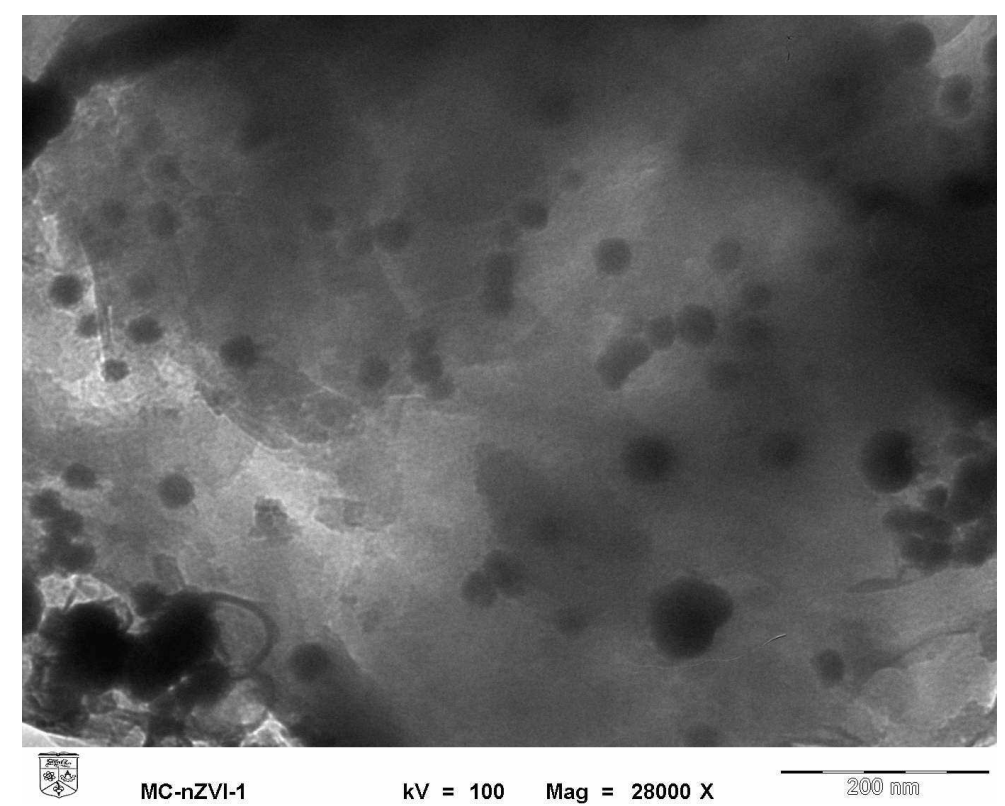

(a)

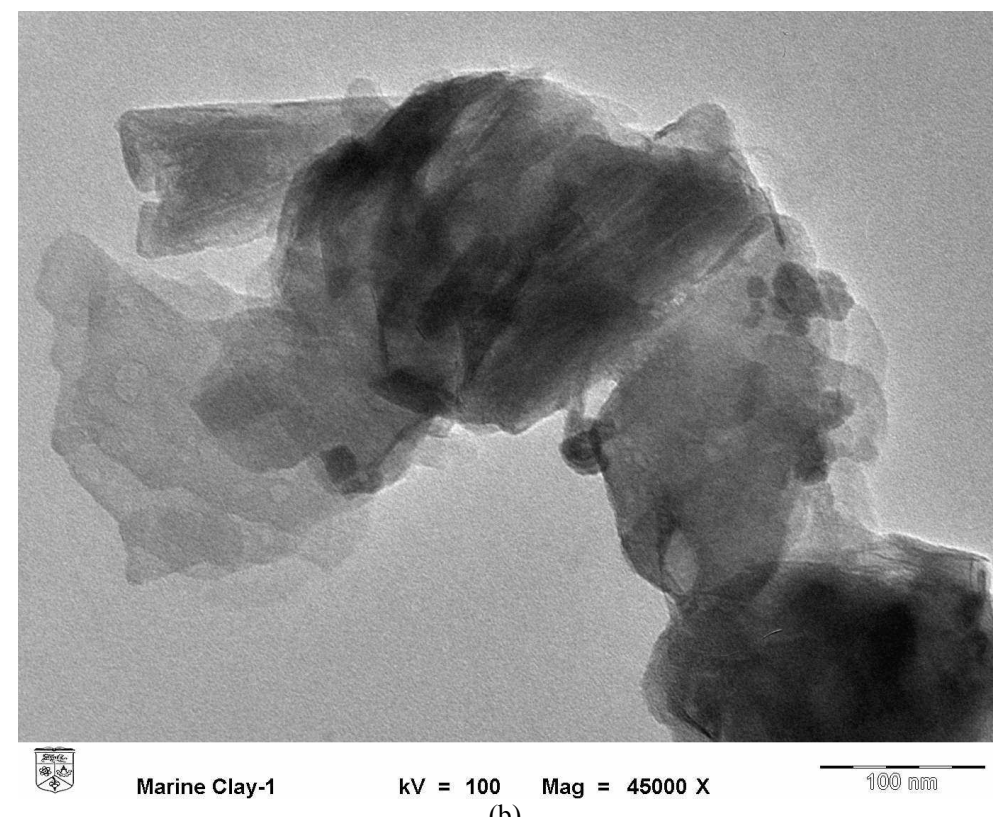

(b)

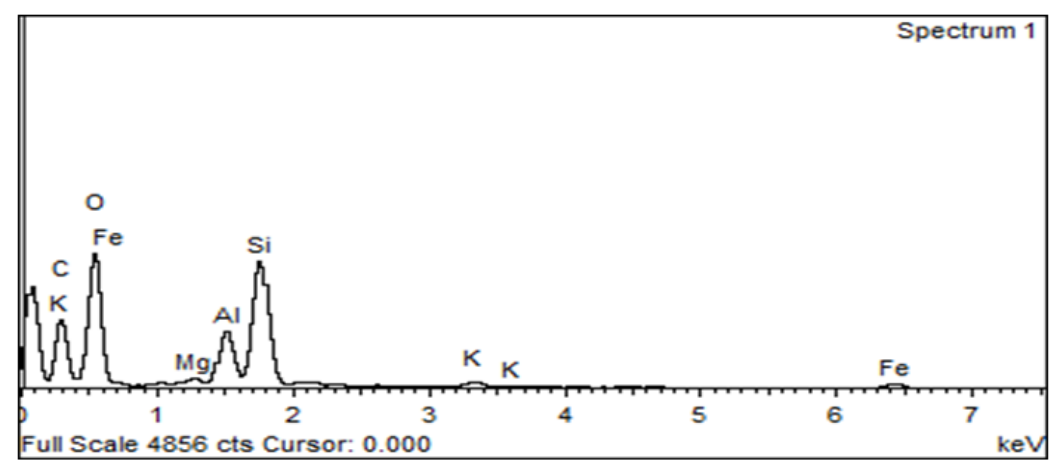

(c) 


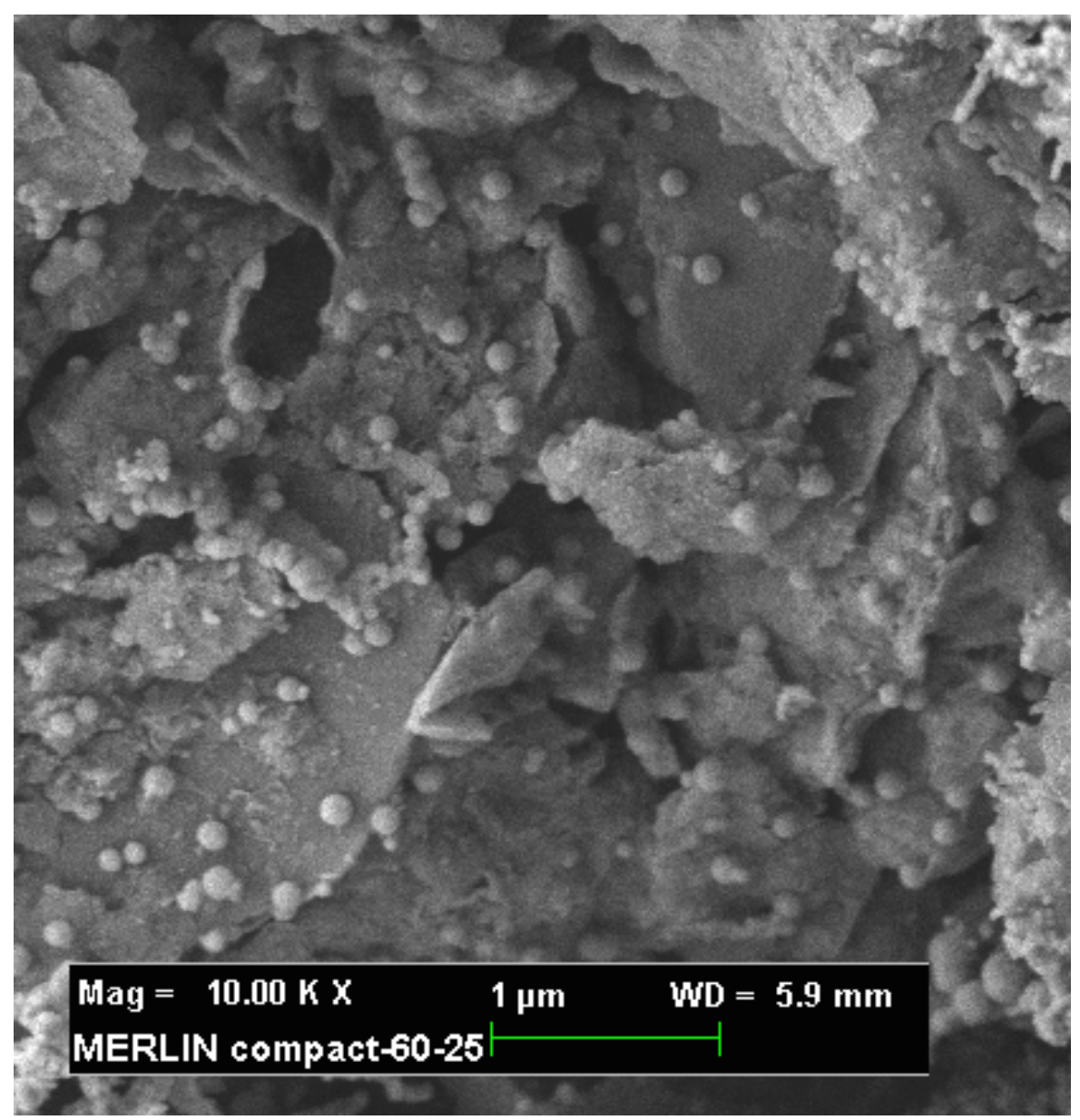

(d)

Fig. 1. (a) TEM image of MC+nZVI (b) TEM image of marine clay (c) EDX of marine clay (d) FESEM of MC+nZVI

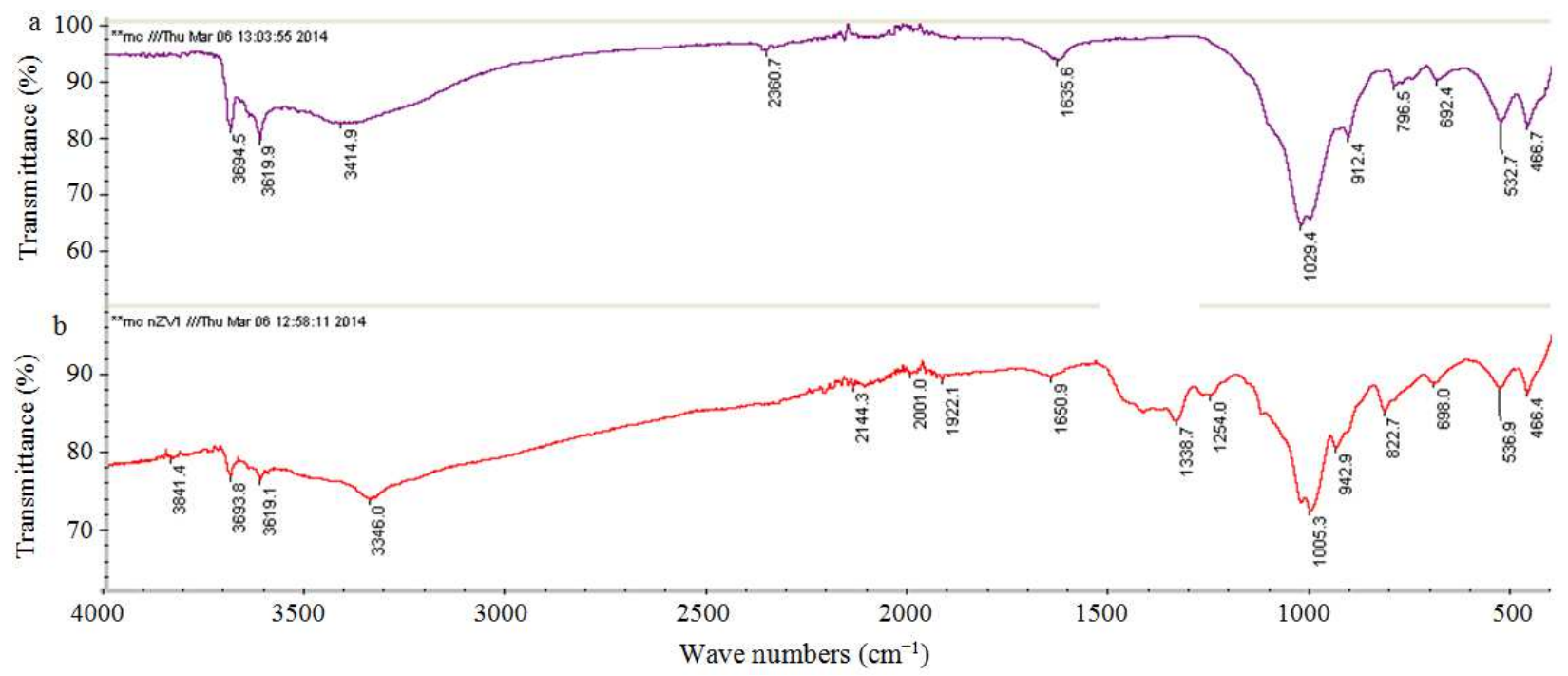

Fig. 2. FTIR Spectrum of (a) marine clay and (b) MC+nZVI 


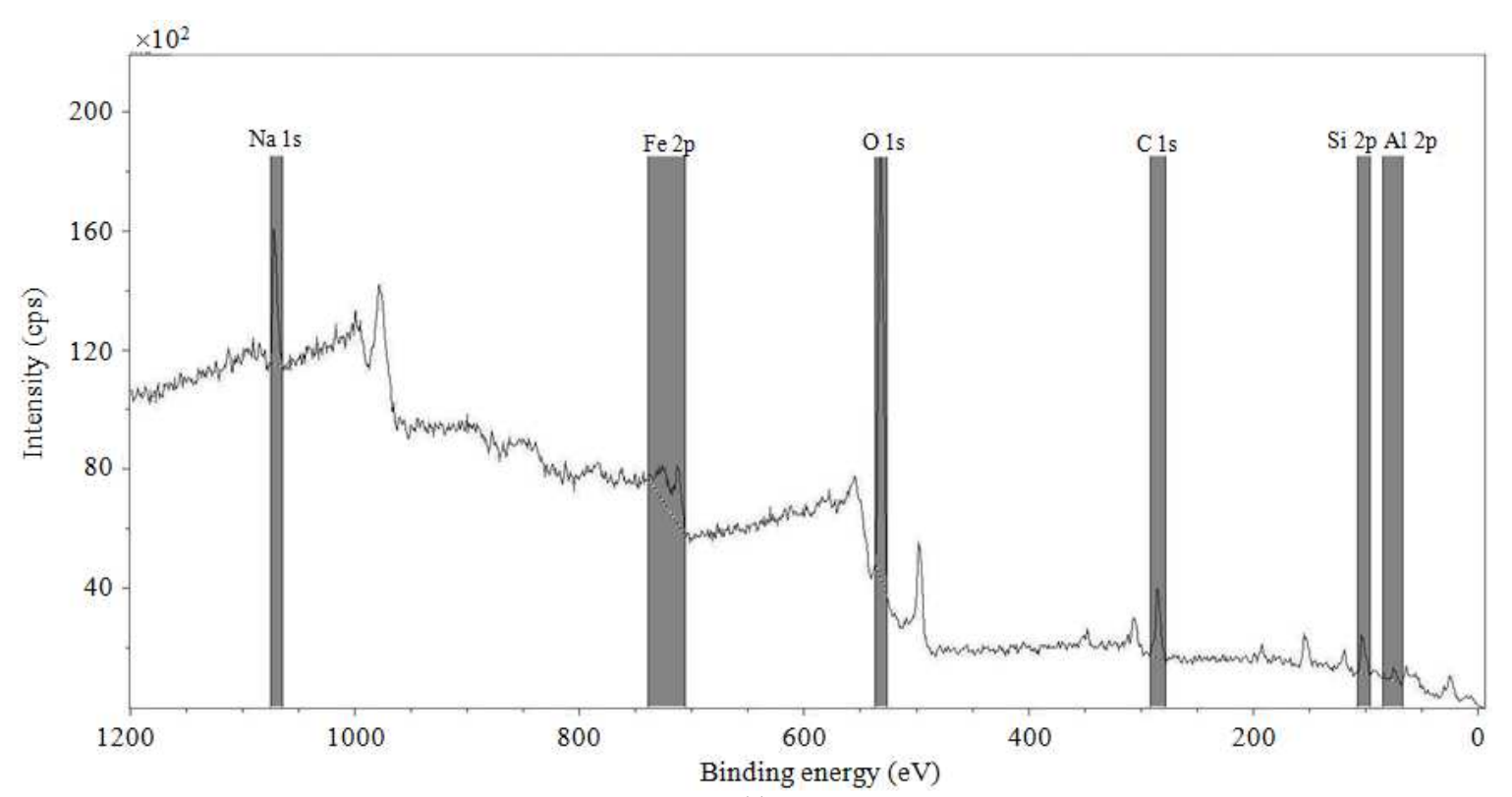

(a)

Fe 2p:4 (mc nZV1)

XPS Spectrum Lens mode: Electrostatic Resolution: Pass energy 20 Iris (Aper): Slot (slot)

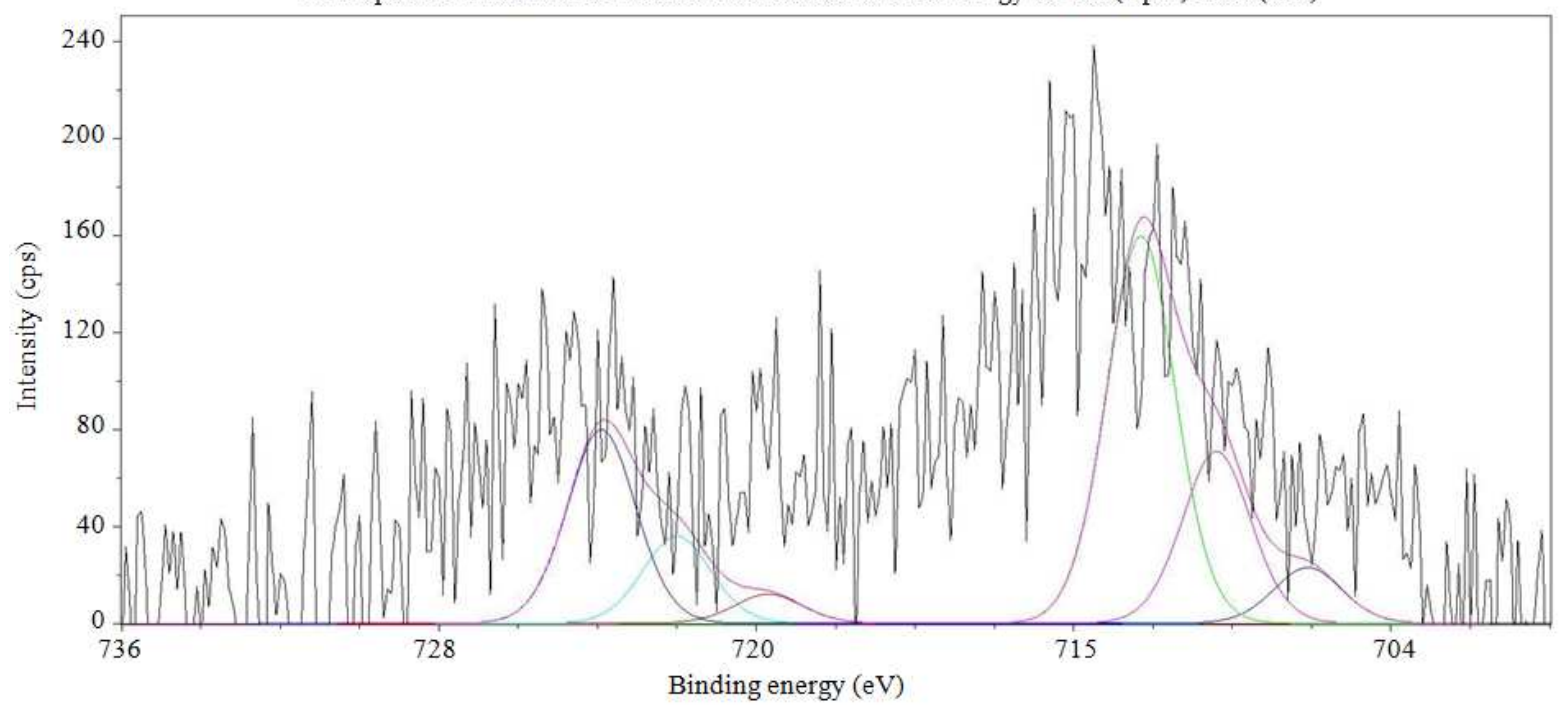

(b)

Fig. 3. XPS profile of (a) full MC+nZVI and (b) Fe 2p line

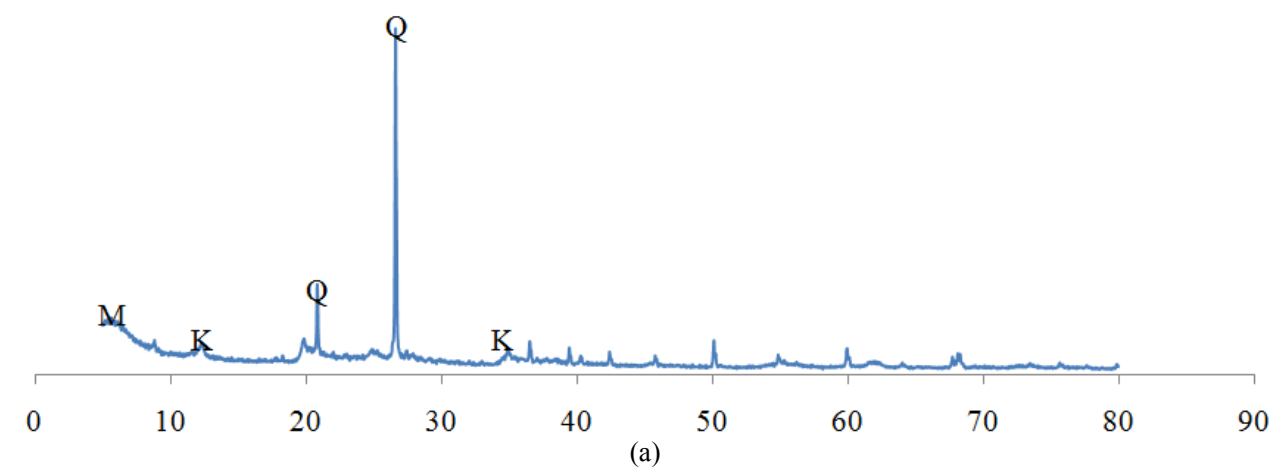




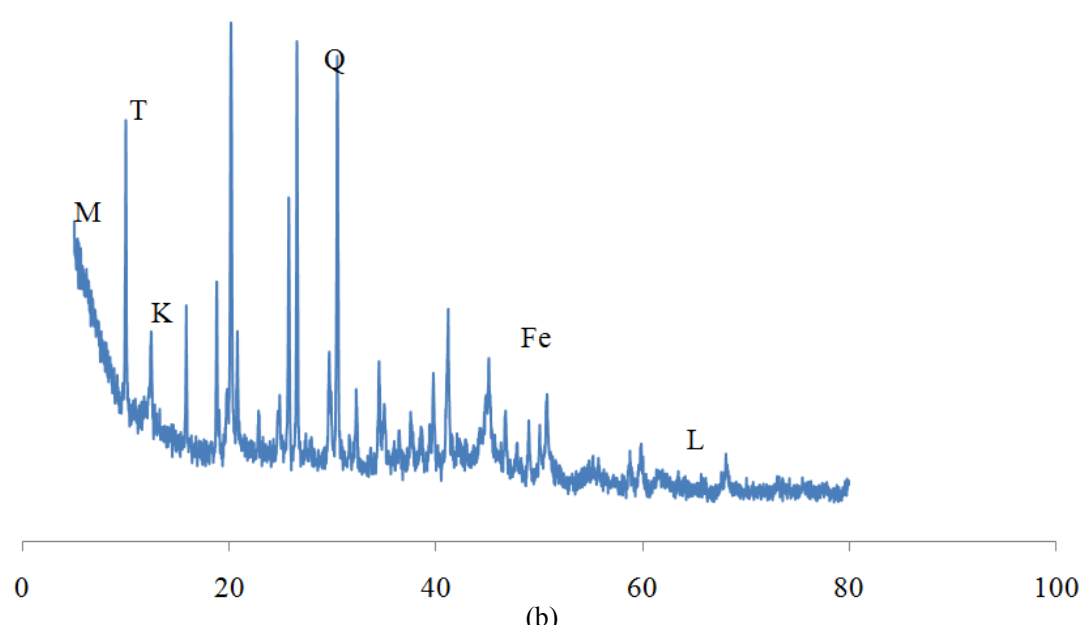

Fig. 4. XRD spectrum for a) marine clay and b) MC+nZVI where M-montmorillonite, T-tincalconite, K-Kaolinite, Q-Quartz, FeIron, L-Lepidocrite

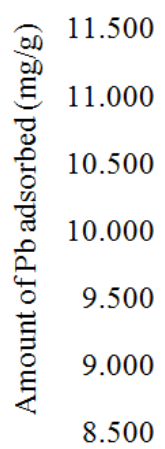

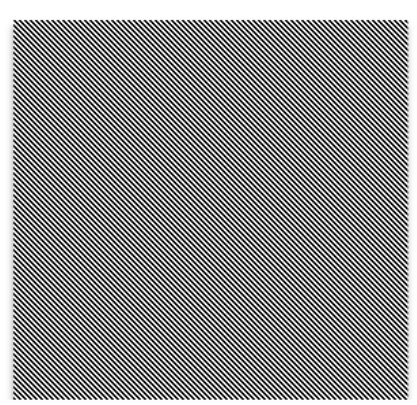

$$
\mathbb{M C}+\mathrm{nZVI}: \mathrm{MC}
$$

Fig. 5. Screening effect of MC+nZVI and marine clay

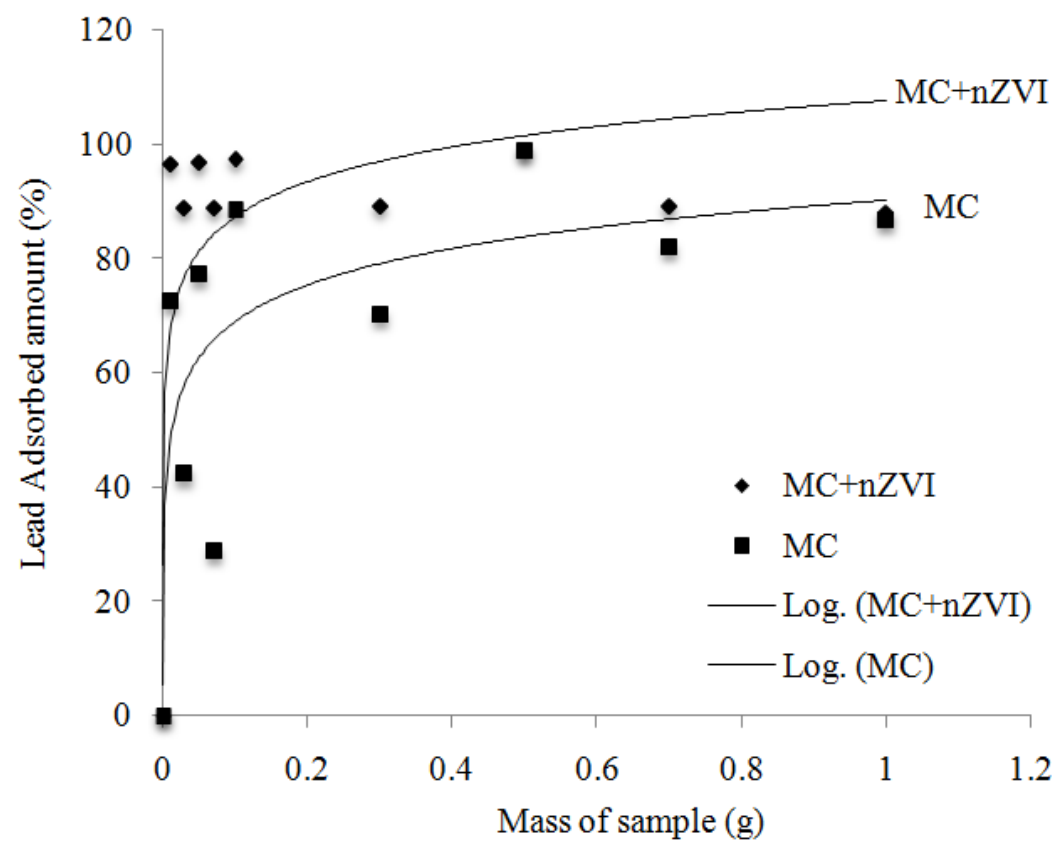

(a) 


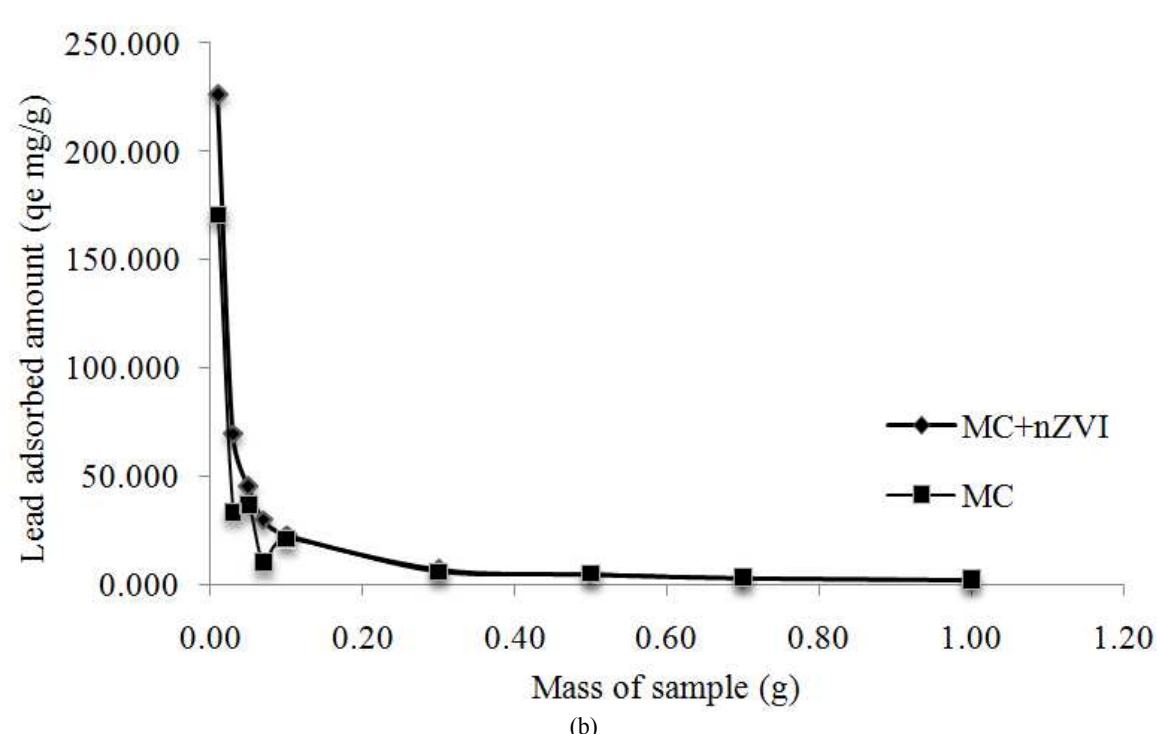

Fig. 6. Effect of marine clay and MC+nZVI dose (a) removal percentage and (b) on adsorbed amount of lead, $\mathrm{q}_{\mathrm{e}}$

\section{Batch Test}

Batch test was conducted to determine the adsorption capability of marine clay and MC+nZVI. Dose effect was first conducted to determine the optimum mass used for adsorption in heavy metal solution.

\section{Screening of Materials}

Screening was conducted to determine the removal capability of marine clay and MC+nZVI. Ratio of the mass of marine clay and MC+nZVI to the volume of the $\mathrm{Pb}$ solution is $1: 10$. The result showed that $\mathrm{MC}+\mathrm{nZVI}$ was more effective in adsorbing $\mathrm{Pb}$ compared to marine clay. As shown in Fig. 5, equilibrium concentration after adsorption of MC+nZVI is $11.318 \mathrm{mg} \mathrm{g}^{-1}$ and marine clay is $9.568 \mathrm{mg} \mathrm{g}^{-1}$. The adsorption capability had increased by $1.75 \mathrm{mg} \mathrm{g}^{-1}$. Increased in the adsorption capacity might be due to the larger specific area provided by the MC+nZVI (Kim et al., 2013; Zhang et al., 2011). Marine clay had acted as a media to prevent aggregation of zero valent iron thus providing more sites for adsorbing lead.

\section{Dose Effect}

Generally, the result showed that the adsorption percentage was increased with the increase of dosage used. Although the graph of adsorption percentage fluctuates, the trend showed that the adsorption percentage of lead had come to equilibrium around $0.3 \mathrm{~g}$ for both marine clay and MC-nZVI. Figure 6a showed that the overall adsorption percentage of MC-nZVI was greater than the marine clay. However, the unit adsorption, $\mathrm{q}_{\mathrm{e}}$ decreased with the increase of dosage used as shown in Fig. 6. This might be the overlapping of particles resulting in overcrowding of the adsorption sites (Hefne et al., 2010). Figure 6 showed the lead adsorbed amount reached equilibrium around $0.3 \mathrm{~g}$ as well. Thus, mass of the samples was fixed at $0.3 \mathrm{~g}$ for further studies on other effect.

\section{Conclusion}

In this study, marine clay has proven that it is suitable to act as a composite material to reduce aggregation of the zero valent iron. So, the zero valent iron can disperse well on the surface of marine clay thus reducing the aggregation. The reduction of aggregation had ensured the size of the particle to be fine which is in nano size thus giving MC+nZVI more sites for the adsorption. MC $+\mathrm{nZVI}$ is able to increase the adsorption capability of marine clay. The adsorption capability had increased $15.46 \%$. In addition, marine clay is an inexpensive resource, which can be obtained easily. Hence, the modification of nZVI with marine clay is a good alternative to synthesis greater adsorption capability nZVI. $\mathrm{MC}+\mathrm{nZVI}$ is readily dispersed in water thus making $\mathrm{MC}+\mathrm{nZVI}$ a good product to remediate water contaminated with lead.

\section{Acknowledgement}

This work was sponsored by the FRGS fund provided by the National University of Malaysia. We are thankful for the assistance provided by Centre For Research and Instrumentation of the National 
University of Malaysia for providing FE-SEM, TEM, XRD and XRF measurements.

\section{Author's Contributions}

Ho Kuok How: Participated in all experiments, acquisition and interpretation of data as well as writing of manuscript.

Wan Zuhairi Wan Yaacob: Coordinated, designed and organized the research study.

\section{Ethics}

This original article discusses on the unpublished materials. All authors have read and approved the manuscript and no ethical issues involved.

\section{References}

Abadin, H., A. Ashizawa, Y.W. Stevens, F. Llados and G. Diamond et al., 2007. Toxicological profile for lead. Agency for Toxic Substances and Disease Registry, Georgia.

Ashraf, M.A., M.J. Maah and I.B. Yusoff, 2010. Study of water quality and heavy metals in soil and water of ex-mining area Bestari Jaya, Peninsular Malaysia. Int. J. Basic Applied Sci., 10: 7-23.

Bhowmick, S., S. Chakraborty, P. Mondal, W. Van Renterghem and S. Van den Berghe et al., 2014. Montmorillonite-supported nanoscale zero-valent iron for removal of arsenic from aqueous solution: Kinetics and mechanism. Chem. Eng. J., 243: 14-23. DOI: $10.1016 /$ j.cej.2013.12.049

Boparai, H.K., M. Joseph and D.M. O'Carroll, 2011. Kinetics and thermodynamics of cadmium ion removal by adsorption onto nano zerovalent iron particles. J. Hazardous Mater., 186: 458-65. DOI: $10.1016 /$ j.jhazmat.2010.11.029

Coates, J., 2000. Interpretation of infrared spectra. A Practical Approach.

Dorathi, P.J. and P. Kandasamy, 2012. Dechlorination of chlorophenols by zero valent iron impregnated silica. J. Environ. Sci., 24: 765-773. DOI: $10.1016 / \mathrm{S} 1001-0742(11) 60817-6$

Frost, R.A.Y.L. and U. Johanssont, 1998. Combination bands in the infrared spectroscopy of kaolins: A drift spectroscopy study. Clays Clay Miner., 46: 466-477. DOI: 10.1346/CCMN.1998.0460411

Giasuddin, A.B.M., S.R. Kanel and H. Choi, 2007. Adsorption of humic acid onto nanoscale zerovalent iron and its effect on arsenic removal. Environ. Sci. Technol., 41: 2022-2027. DOI: 10.1021/es0616534

Hefne, J.A., W.K. Mekhemer, N.M. Alandis, O.A. Aldayel and T. Alajyan, 2010. Removal of Silver (I) from Aqueous Solutions by Natural Bentonite. JKAU, 22: 155-176. DOI: 10.4197 / Sci. 22-1.11
Kanel, S.R., B. Manning, L. Charlet and H. Choi, 2005. Removal of arsenic(III) from groundwater by nanoscale zero-valent iron. Environ. Sci. Technol., 39: 1291-1298. DOI: 10.1021/es048991u

Kim, S.A., S. Kamala-Kannan, K.J. Lee, Y.J. Park and P.J. Shea et al., 2013. Removal of $\mathrm{Pb}(\mathrm{II})$ from aqueous solution by a zeolite-nanoscale zero-valent iron composite. Chem. Eng. J., 217: 54-60. DOI: 10.1016/j.cej.2012.11.097

Kim, Y.C., H.H. Park, J.S. Chun and W.J. Lee, 1994. Compositional and structural analysis of aluminum oxide films prepared by plasma-enhanced chemical vapor deposition. Thin Solid Films, 237: 57-65. DOI: 10.1016/0040-6090(94)90238-0

Lin, Y.H., H.H. Tseng, M.Y. Wey and M.D. Lin, 2010. Characteristics of two types of stabilized nano zero-valent iron and transport in porous media. Sci. Total Environ., 408: 2260-7. DOI: $10.1016 /$ j.scitotenv.2010.01.039

Liu, T., Z.L. Wang, X. Yan and B. Zhang, 2014. Removal of mercury (II) and chromium (VI) from wastewater using a new and effective composite: Pumice-supported nanoscale zero-valent iron. Chem. Eng. J., 245: 34-40. DOI: 10.1016/j.cej.2014.02.011

Mystrioti, C., D. Sparis, N. Papassiopi, A. Xenidis and M. Chrysochoou, 2012. Hexavalent Chromium reduction with polyphenol-coated nano zero valent iron.

O'Carroll, D., B. Sleep, M. Krol, H. Boparai and C. Kocur, 2013. Nanoscale zero valent iron and bimetallic particles for contaminated site remediation. Adv. Water Resources, 51: 104-122. DOI: 10.1016/j.advwatres.2012.02.005

Phenrat, T., N. Saleh, K. Sirk, R.D. Tilton and G.V. Lowry, 2007. Aggregation and sedimentation of aqueous nanoscale zerovalent iron dispersions. Environ. Sci. Technol., 41: 284-290. DOI: $10.1021 / \mathrm{es} 061349 \mathrm{a}$

Poursaberi, T., M. Hassanisadi and F. Nourmohammadian, 2012. Application of synthesized nanoscale zero-valent iron in the treatment of dye solution containing basic yellow 28. Progress Color Colorants Coat., 5: 35-40.

Su, C., R.W. Puls, T.A. Krug, M.T. Watling and S.K. O'Hara et al., 2012. A two and half-yearperformance evaluation of a field test on treatment of source zone tetrachloroethene and its chlorinated daughter products using emulsified zero valent iron nanoparticles. Water Res., 46: 5071-5084.

Sun, Y.P., X. Li, J. Cao, W. Zhang and H.P. Wang, 2006. Characterization of zero-valent iron nanoparticles. Adv. Colloid Interface Sci., 120: 47-56. DOI: 10.1016/j.cis.2006.03.001 
Tiraferri, A. and R. Sethi, 2008. Enhanced transport of zerovalent iron nanoparticles in saturated porous media by guar gum. J. Nanoparticle Res., 11: 635-645. DOI: $10.1007 / \mathrm{s} 11051-008-9405-0$

Uzum, C., T. Shahwan, A. Eroglu, K. Hallam and T. Scott et al., 2009. Synthesis and characterization of kaolinite-supported zero-valent iron nanoparticles and their application for the removal of aqueous $\mathrm{Cu}^{2+}$ and $\mathrm{Co}^{2+}$ ions. Applied Clay Sci. 43: 172-181. DOI: 10.1016/j.clay.2008.07.030

Yuan, P., F. Annabi-Bergaya, Q. Tao, M. Fan and Z. Liu et al., 2008. A combined study by XRD, FTIR, TG and HRTEM on the structure of delaminated Feintercalated/pillared clay. J. Colloid Interface Sci., 324: 142-9. DOI: 10.1016/j.jcis.2008.04.076
Yuan, P., M. Fan, D. Yang, H. He and D. Liu et al., 2009. Montmorillonite-supported magnetite nanoparticles for the removal of hexavalent chromium $[\mathrm{Cr}(\mathrm{VI})]$ from aqueous solutions. J. Hazardous Mater., 166: 821-9. DOI: 10.1016/j.jhazmat.2008.11.083

Zhang, X., S. Lin, Z. Chen, M. Megharaj and R. Naidu, 2011. Kaolinite-supported nanoscale zerovalent iron for removal of $\mathrm{Pb}^{2+}$ from aqueous solution: Reactivity, characterization and mechanism. Water Res., 45: 3481-8.

DOI: $10.1016 /$ j.watres.2011.04.010

Zhang, X., S. Lin, X.Q. Lu and Z. Chen, 2010. Removal of $\mathrm{Pb}$ (II) from water using synthesized kaolin supported nanoscale zero-valent iron. Chem. Eng. J., 163: 243-248. DOI: 10.1016/j.cej.2010.07.056 